\title{
fAMILIARES de CLIENTES ACOMETIdOS PELO hIVIAIDS E O ATENDIMENTO PRESTAdo EM UMA UNIDAdE AMBULATORIAL
}

\author{
Edilene Aparecida Araújo da Silveira ${ }^{1}$ \\ Ana Maria Pimenta Carvalho ${ }^{2}$
}

Silveira EAA da, Carvalho AMP. Familiares de clientes acometidos pelo HIVIAIDS e o atendimento prestado em uma unidade ambulatorial. Rev Latino-am Enfermagem 2002 novembro-dezembro; 10(6):813-8.

Durante o desenvolvimento da doença ocorrem alterações no estilo de vida do indivíduo com HIVIAIDS que suscitam, na família e no paciente, reações de adaptação às demandas. O presente estudo, realizado no ambulatório de um centro de referência para HIVIAIDS, contou com a participação de oito integrantes do grupo de apoio para familiares de pacientes acometidos pelo HIVIAIDS. Eles responderam a uma entrevista semi-estruturada a partir da qual foram analisados os conteúdos de suas falas. Esses familiares referiram dificuldades ao lidar com a doença e com a agressividade do paciente em relação ao cuidador. Eles encontraram acolhimento e recursos que proporcionaram melhora da saúde e mudanças positivas no paciente, mas queixaram-se da demora no atendimento ambulatorial e dificuldades com o transporte. No grupo de apoio encontraram alívio e conforto. A família que se propõe a cuidar do paciente deve ser acolhida e auxiliada na adaptação às mudanças, pela equipe de saúde.

DESCRITORES: síndrome de imunodeficiencia adquirida, família, ambulatório

\section{RELATIVES OF GLIENTS WITH HIVIAIDS AND THE CARE PROVIDED AT AN} OUTPATIENT UNIT

During the development of AIDS, there are changes in the life style of HIV-positive individuals which give rise to adaptation to the new demands within the family. This study, conducted in the outpatient unit of a reference center for HIVIAIDS, had eight participants from the group of relatives of HIV-positive patients. They participated in semi-structured interviews, whose contents were analyzed. These relatives referred to difficulties in dealing with the disease and the patients' aggressiveness in relation to the caretaker. They reported the receipt of resources that enabled them to improve health as well as positive changes regarding the patients, but complained about the delay in care delivery and transportation difficulties. They found relief in the support group. Families that are committed to provide the care to the patients must be received and helped by the healthcare team during adaptation to changes.

\section{FAMILIARES DE PACIENTES AFECTADOS POR ÉL HIVISIDA Y EL CUIDADO DADO EN UNA UNIDAD dE SERVICIO AMBULATORIO}

Durante el desarrollo de la enfermedad ocurren alteraciones en la forma de vida del individuo con HIVIAIDS que suscitan en la familia y en el paciente, reacciones de adaptación a la demanda. El presente estudio fue realizado en el servicio de consulta externa de un Centro de Referencia para HIVAIDS. Participaron de esta investigación 8 familiares que forman parte del grupo de apoyo para familiares de pacientes con HIV. Cada participante fue entrevistado y posteriormente los relatos fueron analizados: Estos familiares refirieron dificultades para lidiar con la enfermedad y con la agresividad del paciente en relación con el cuidador. Ellos encontraron acogimiento u recursos que proporcionan mejoras en la salud y cambios positivos en el paciente, pero se quejaron de la demora en la atención ambulatoria y dificultades con el transporte. En el grupo de apoyo encontraron alivio y confort. La familia que se propone cuidar del paciente debe ser acogida y ayudada por el equipo de salud para facilitar su adaptación a los cambios.

DESCRIPTORES: síndrome de inmunodeficiencia adquirida, familia, ambulatorio

\footnotetext{
${ }^{1}$ Enfermeira, Especialista em Enfermagem Psiquiátrica, Mestranda em Enfermagem Psiquiátrica, e-mail: edileneap@yahoo.com.br; ${ }^{2}$ Professor Assistente Doutor, e-mail: anacar@eerp.usp.br. Escola de Enfermagem de Ribeirão Preto da Universidade de São Paulo, Centro Colaborador da OMS para o desenvolvimento da pesquisa em enfermagem
} 


\section{INTRODUÇÃO}

$\boldsymbol{P}_{\text {oucas doenças têm suscitado questões tão }}$ complexas quanto a Aids em todos os segmentos onde $o$ soropositivo se encontra circunstanciado.

Ao longo do desenvolvimento da doença ocorrem perdas significativas na vida do indivíduo afetado, tais como saúde, aparência física e família ${ }^{(1)}$. Impõe-se a necessidade de hábitos em decorrência da doença, ingerir medicamentos, conviver com a ameaça do aparecimento de doenças oportunistas e da morte em vida. Essas alterações no cotidiano suscitam, na família e no paciente, reações de adaptação às demandas e mudam o relacionamento com a sociedade.

Além disso, a AIDS tem um efeito desagregador na estrutura familiar, que não raro já se encontrava abalada por questões tais como drogadição, ausência de alguma figura parental, envolvimento criminal e outras atitudes tidas como "transgressoras" pela sociedade ${ }^{(2)}$. Portanto, o portador do HIV não é o único a sofrer as conseqüências; seus familiares, amigos e parceiros sexuais também irão enfrentar junto com ele as dificuldades tais como preconceito e estigma ${ }^{(3)}$.

Nesse âmbito, a família pode ser definida como sendo um grupo formado por pessoas unidas por laços afetivos consangüíneos ou não, inseridas em um contexto social e temporal. Devido à abrangência da definição, no presente estudo consideremos que o parente ou cuidador é a pessoa a quem o paciente recorre.

Essa pessoa irá enfrentar muitos fatores que influenciarão suas reações durante o desenvolvimento da doença de seu ente, que a colocará num contínuo entre a colaboração/solidariedade e conflitos/discriminação ${ }^{(4)}$. Esses fatores podem ser exemplificados pela instabilidade emocional provocada pelo curso variável da doença, expectativa de vida curta para o paciente e tratamentos complexos. O familiar passa, ainda, por fases da vivência da doença grave e preparo para a morte, que se sincronizam com aquelas vivenciadas pelo doente ${ }^{(5)}$. Isso gera sofrimento e remete à necessidade da busca de suporte, o qual pode ser fornecido pelo serviço de saúde. A finalidade desse suporte é ajudar o familiar a permanecer ao lado do cliente.

O profissional de saúde, porém, em geral, enfrenta diversas dificuldades internas e externas que influenciam no atendimento prestado ${ }^{(6)}$.

No exercício da profissão junto a essa clientela, temos percebido que tais dificuldades são vivenciadas por todos aqueles que realizam o atendimento e em especial pela enfermagem. Elas atrapalham tanto o relacionamento da equipe com o familiar como podem afastá-lo da convivência com o cliente. Esse aspecto é importante quando observamos que, de modo geral, o paciente gostaria de contar com o apoio de seus familiares. Essa participação pode ser tão importante a ponto de se tornar o principal motivo para que o indivíduo continue vivendo ${ }^{(7)}$.

Percebendo a importância que a família tem para a sobrevida do individuo soropositivo e as possíveis dificuldades no atendimento, nosso objetivo no presente estudo foi entender a percepção que os familiares têm sobre o tratamento que recebem em uma unidade especializada num hospital geral e sobre sua participação em um grupo de familiares que vivenciam a mesma doença.

\section{MÉTODO}

Local de realização do estudo

O presente estudo foi realizado no ambulatório da Unidade Especializada de Tratamento de Doenças Infecciosas (UETDI) do Hospital das Clínicas da Faculdade de Medicina de Ribeirão Preto da Universidade de São Paulo, que é um centro de referência.

A unidade atende a pacientes da rede pública de todas as idades que se apresentam na fase de doença AIDS, procedentes de Ribeirão Preto e região.

Além do atendimento médico, de enfermagem e psicológico, essas pessoas poderão participar de atividades em grupo.

Os clientes e familiares vêm ao retorno médico pré-agendado. Enquanto aguardam a chamada para a consulta podem, às segundas e quintas-feiras pela manhã, participar de grupos. Os pacientes participam do grupo de sala de espera, onde aprendem sobre a doença, tratamento, prevenção, etc. através de vídeos e palestras. Paralelamente, os familiares também se reúnem, com a finalidade de trocar experiências, informações e discutirem assuntos relacionados à doença ou ao tratamento. $\mathrm{O}$ número de pacientes varia devido a fatores tais como a morte de pacientes, início de tratamento ou mudança de local para tratamento clínico, do número de atendimentos clínicos diários e da aceitação do familiar em participar do grupo.

Por se constituir objeto da presente investigação, nos ateremos somente ao grupo de familiares. As reuniões 
têm, em média, duração de uma hora e trinta minutos. A coordenação fica a cargo de um profissional escalado para aquele dia. Não há pauta inicial. Um familiar é apresentado ao outro e aos profissionais participantes daquele dia. Cada um deles inicia falando sobre as dificuldades/facilidades que está enfrentando no contexto das relações com o paciente e seu tratamento. Enquanto isso, os outros familiares e profissionais escutam e trazem experiências que podem ajudá-lo. Os assuntos portanto, a serem discutidos são suscitados durante a reunião.

O recrutamento para o grupo ocorre através de cartazes espalhados pela unidade, encaminhamento pelos vários profissionais e convite às pessoas que aguardam consulta.
Sujeitos

Oito familiares, sendo cinco mães, duas irmãs e uma filha, fizeram parte desse estudo.

Foram considerados os seguintes critérios para a inclusão dos familiares no estudo: o paciente deveria ter diagnóstico confirmado de HIV, estar em acompanhamento médico na unidade e estar ciente de seu diagnóstico. $\mathrm{O}$ familiar deveria estar ciente do diagnóstico, estar acompanhando o tratamento médico, ter participado do grupo de familiares pelo menos duas vezes e aceitar participar do estudo.

A Figura 1 apresenta a caracterização dos pacientes cujos familiares foram entrevistados.

\begin{tabular}{|c|c|c|c|c|c|c|c|}
\hline Sujeito & Idade & Sexo & Profissão & Estado Civil & Ano Soro- & Trans- & Familiar \\
& & & & & conversão & missão & M1 \\
\hline MAP & 30 & $\mathrm{M}$ & inativo & solteiro & 1999 & R. sexual & (mãe) \\
\hline ARJ & 38 & $\mathrm{M}$ & inativo & amaziado & 1995 & UDI & M2 \\
\hline RDG & 29 & $\mathrm{M}$ & inativo & solteiro & 1992 & UDI & M3 \\
\hline COC & 26 & $\mathrm{M}$ & Guarda & solteiro & 2000 & UDI & M4 \\
\hline EAON & 33 & $\mathrm{M}$ & Lavrador & casado & 1995 & UDI & M5 \\
\hline AAM & 34 & $\mathrm{M}$ & Motorista & desquitado & 1995 & UDI & I1 \\
\hline EAON* & 33 & $\mathrm{M}$ & Lavrador & casado & 1995 & UDI & (irmã) \\
\hline EB & 60 & $\mathrm{~F}$ & Dona de & viúva & 2000 & R. sexual & F1 \\
\hline
\end{tabular}

* paciente cujas mãe e irmã foram entrevistadas, em dias diferentes

Figura 1 - Caracterização dos pacientes acometidos pelo HIV cujas famílias foram entrevistada

Conforme a caracterização demográfica apresentada na Figura 1 podemos perceber, nesse grupo de pacientes, que a faixa etária predominante variou de 21 a 40 anos (7 pessoas), que coincide com a prevalência no país, durante o período de 1980 a $2000^{(8)}$. Os indivíduos adoecem numa fase produtiva da vida, quando podem ter maiores dificuldades financeiras diante do oneroso gasto com a doença ${ }^{(7)}$.

A maioria é composta pelo sexo masculino (7 pessoas). O número de casos notificados tem diminuído desde 1998, porém a relação homem/mulher tem reduzido de 3:1 em 1998 para 2:1, em $2000^{(8)}$, o que é preocupante devido ao risco de transmissão vertical.

Cinco pessoas acreditam que se contaminaram devido ao uso de agulhas e seringas contaminadas compartilhadas.

Procedimento - coleta de dados

Enviamos para o Hospital das Clínicas o projeto 
de pesquisa para a apreciação do Comitê de Ética daquela instituição. Após autorização, iniciamos a coleta de dados.

Antes que a entrevista se iniciasse, explicávamos os objetivos da investigação e perguntávamos se a pessoa concordaria em participar. Quando a resposta era positiva, o familiar juntamente com o pesquisador liam o termo de consentimento em voz alta. Após esclarecimento de dúvidas, o familiar assinava o termo.

Para a coleta de dados foi utilizada entrevista semi-estruturada na qual constavam as seguintes perguntas:

1. como você, enquanto família, tem vivenciado a experiência de ter um membro com a doença AIDS?

2. faça uma avaliação do atendimento que você e seu familiar recebem;

3. faça uma avaliação da reunião da qual você participou.

Nenhum dos familiares permitiu que as entrevistas fossem gravadas. Consentiram que fossem feitas anotações durante a entrevista.

\section{Análise dos Dados}

As entrevistas foram analisadas extraindo-se delas os conteúdos temáticos considerados como correspondentes à totalidade da fala dos sujeitos ${ }^{(9)}$.

Para essa análise foram realizadas várias leituras por dois profissionais e suas propostas de categorização foram comparadas até que se chegasse a um conteúdo consensual.

\section{RESULTADOS E DISCUSSÃO}

Os resultados da análise das entrevistas serão apresentados considerando-se, como elemento que precederam as falas dos entrevistados, as questões propostas pela pesquisadora.

Durante o desenvolvimento da doença, o doente precisará de um cuidador para auxiliá-lo em tarefas que não consegue fazer de modo efetivo e independente ${ }^{(7)}$. Isso poderá garantir melhor sobrevida. Dentre os cuidadores, em nosso estudo, verificamos que as mães são as mais presentes.

A mãe apresenta um forte sentimento de solidariedade em relação ao filho portador. A dor de perder um filho e o sentimento de discriminação estão interagindo ativamente $^{(7)}$. As pessoas adoecem e tendem a voltar à casa materna onde são recebidos pela mãe $\mathrm{e}^{(1)}$.

Ao assumir esse cuidado, a mãe e/ou o cuidador vivenciam a experiência de ter um parente acometido pelo HIV, podendo passar pelas fases de enfrentamento de uma doença grave e preparo para a morte, permanecendo num contínuo entre o cuidar e o abandono ${ }^{(4)}$.

Por outro lado, a AIDS é uma doença que pode assumir diversos cursos, pois seu desenvolvimento depende da carga viral (número de cópias virais no organismo) e da velocidade/gravidade com que o vírus afeta o sistema imunológico do hospedeiro. Exige idas constantes ao médico, submissão a variados exames e tratamentos prolongados, mudanças no cotidiano familiar, dificuldades em lidar com a doença e com a rotina do tratamento. Nesse contexto, sentir-se acolhido é fundamental para que se prossiga na luta contra a doença.

Tanto o meu filho quanto eu somos bem tratados aqui. Já teve um dia em que eu estava com fome e até almoço me serviram. M2.

Os tratamentos são complexos e o paciente ingere muitas medicações diferentes durante a agudização da doença e de aparecimento de doenças oportunistas, quando o familiar pode enfrentar dificuldades em lidar com o aparecimento da sintomatologia e esperar o tempo necessário para o tratamento apresentar resultados. Nessa fase, pode surgir a necessidade de internação.

... é difícil porque ele já teve várias complicações e eu fico desesperada. Ele já teve hepatite, tuberculose, aneurisma, usava drogas e por isso teve a perna amputada. M2.

Nesse contexto, as informações dadas pela equipe de saúde podem ajudar a família a superar as dificuldades e permanecer ao lado do paciente. Elas devem ser transmitidas com cuidado para não assustar ou confundir o familiar.

Além de barreiras como a doença e o tratamento, o familiar ainda pode enfrentar a agressividade do paciente em relação ao cuidador.

Durante a fase de raiva, o paciente pode apresentar hetero e auto-agressão física e verbal. Esse sentimento de raiva pode ser reforçado pelas perdas significativas que vão ocorrendo ao longo do desenvolvimento da doença, comprometendo o relacionamento com a pessoa envolvida no cuidado.

...no início ele era malcriado comigo...M1.

...ruim... Ele é agressivo, quase não conversa. M5.

Por outro lado, algumas pessoas que possivelmente já apresentavam dificuldades em relação à 
adesão a regras podem ter dificuldades em seguir prescrições impostas pelo tratamento, doença, instituição de saúde e mesmo pelo ambiente onde vive. Isso pode originar comportamentos agressivos por parte do cliente.

...Ele fica nervoso, principalmente quando tem diarréia, vômito e dor de estômago. Briga muito com a mãe porque ela não entende e fica perguntando. 12.

Antes ele era agressivo, mas agora piorou... Por exemplo, ele mijava na soleira da porta, falava que tomava o remédio e não tomava ou então tomava dose dobrada, recusava tomar banho. 11.

A filha evita falar sobre a doença, pois havia pouco tempo que sabia sobre o diagnóstico. Essa reação remete ao processo de negação ${ }^{(5)}$. O familiar nega-se a falar sobre a doença e a aceitar a realidade.

Lá em casa evitamos falar sobre o assunto. Faz menos de um mês que soubemos do diagnóstico... F1.

Diante dos problemas que surgem no ambiente familiar, a equipe de saúde deve estar atenta e ajudar a família a enfrentar a realidade e a se adaptar de modo mais efetivo.

Entretanto, nem sempre os profissionais encontram-se preparados $^{(7)}$. Sentem-se questionados a todo instante e enfrentam pressões externas e internas que influenciam no atendimento prestado.

No contexto de avaliação atendimento, foi apontado por familiares problemas de ordem prática.

A única coisa ruim é que a gente chega cedo e passam outras pessoas que chegaram mais tarde na nossa frente... M3.

O meu maior problema é a ambulância que demora para ir buscar... M2.

O volume de atendimentos prestados pelo ambulatório e pela unidade de internação e a complexidade do tratamento exigem que o médico demore em atender cada paciente dando esclarecimentos necessários. Esses fatores aumentam a espera, gerando desconforto e irritação por parte dos usuários dos serviços.

No caso do transporte, ele é executado pela prefeitura. Quando surge uma urgência, a ambulância é requisitada a atender primeiramente a urgência para depois buscar o paciente da unidade, apesar do transporte já estar requisitado.

Houve relatos de contribuições do tratamento para mudanças positivas no paciente após o início do tratamento e da disponibilidade de recursos materiais bons.

...eu gosto. Você vê, ele ficou internado e depois disso só hábitos higiênicos melhoraram. Ele já não mija em qualquer lugar, melhorou para tomar medicamentos e as cinzas do cigarro ele joga no lixo. 11.

Bom. Nós moramos em Jaboticabal e lá não tem recursos. Aqui tem tudo o que precisa fazer. É mais fácil. 12.

A unidade de atendimento está situada num hospital universitário e, portanto, possui recursos materiais que outros hospitais de porte menor não possuem.

As mudanças positivas provocadas no paciente provavelmente não foram resultado somente do atendimento prestado. Pode ser resultado também da presença no grupo de pacientes. É uma das oportunidades em que o paciente é escutado e pode contribuir com os outros a partir de sua experiência pessoal, ao mesmo tempo em que outros podem ajudá-lo a entender melhor sua doença, gerando entre outros sentimentos, o da compreensão.

Quando o indivíduo sente-se compreendido de maneira sensível e correta, ele desenvolve um conjunto de atitudes promotoras de crescimento ou terapêuticas em relação a si mesmo que são percebidas pela família como mudanças positivas, proporcionadas pelo atendimento $^{(10)}$.

No grupo onde participam os familiares são discutidos assuntos que podem ajudá-los a lidar com a demanda exigida pela doença e pelo tratamento.

Dentre os participantes deste estudo, foi relatado a sensação de alívio/conforto e oportunidade de desabafo.

Foi ótima a reunião pela ajuda, conforto e orientação que eles nos dão. M1.

Bom porque desabafa. M5.

...A gente sai aliviada, confortada. M4.

A reunião é boa porque propõe ajuda se a gente quiser. $A$ gente pode ajudar outras pessoas através do exemplo do que aconteceu comigo... M3.

É bom porque cada um fala do problema. A doença é a mesma, mas os problemas é que são diferentes. M2.

Essas duas questões aparecem interligadas uma vez que a sensação de alívio/conforto pode ser proporcionada pela oportunidade de desabafo.

É bom porque dá para desabafar... F1.

No grupo, todos (profissionais e familiares) escutam cada familiar. Assim a pessoa tem mais uma oportunidade de falar sobre suas dificuldades e ter alguém para escutá-la. As outras pessoas ainda podem sugerir soluções através de sua experiência de vida.

A filha não quis avaliar o atendimento prestado 
devido ao pouco contato com a equipe, mas referiu que a participação no grupo proporcionou a oportunidade de falar de coisas das quais não se fala em casa.

Podemos perceber que, apesar de estar, provavelmente na fase de negação ou mesmo de choque frente ao diagnóstico recente da mãe, a filha pode aproveitar o espaço criado pelo grupo para falar de algo que a estava incomodando e que até aquele momento não tinha conseguido falar.

Esse momento é muito importante pois a família está decidindo se irá ou não cuidar do doente. Ela deve estar ansiosa, surpresa e com muitas dúvidas. Uma boa intervenção da equipe de saúde, numa oportunidade como o espaço criado pelo grupo pode garantir a participação da família, reduzir a ansiedade e resolver dúvidas. Assim ela poderá colaborar melhor no tratamento.

\section{CONCLUSÃO}

A família que se propõe a cuidar do membro atingido enfrenta muitos problemas. Ela é peça fundamental no tratamento e o paciente a quer perto de si. Mas para que a família possa ajudar é preciso que a equipe de saúde se proponha a ajudá-la nas dificuldades que surgirem ao longo do desenvolvimento da doença. $E$ essa ajuda pode iniciar-se na escuta do familiar/ cuidador num trabalho grupal.

Ela pode ser importante tanto para o profissional como para o familiar, pois, além do alívio e espaço para relatar problemas que ocorrem em conseqüência da doença e para o aprendizado, fornece um feedback para os profissionais sobre o atendimento prestado, além de possibilitar a criação de vínculos benéficos.

\section{REFERÊNCIAS BIBLIOGRÁFICAS}

1. Zaleski EGF O sentido de vida do portador de síndrome da Imunodeficiência Adquirida: uma questão de saúde mental para ações de enfermagem. [dissertação]. Ribeirão Preto (SP): Escola de Enfermagem de Ribeirão Preto/USP; 1996. 2. Souza NR, Vietta EP Compreendendo o portador HIVIAIDS - usuário de drogas. J Bras Doenças Transm 1999; 11(5):317.

3. Flaskerud JH Psychosocial aspects. J Ppsychosoc Nurs; 1987; 25(12):9-16.

4. Castro R, Eroza E, Orozco E, Manca MC, Hernandéz JJ Estratégias de manejo en torno al VIH/SIDA a nível familiar. Salud Publica Méx 1997 enero-febrero; 39(1):32-43.

5. Kubler-Ross E Sobre a morte e o morrer. 3. ed. São Paulo (SP): Martins Fontes; 1989.

6. Moura L, Jacquemin A Aspectos psicossociais da Síndrome da Imunodeficiência adquirida. Rev Saúde Pública 1991; 25(2):159-62.

7. Souza NR Compreendendo o portador HIVIAIDS - usuário de drogas, segundo o modelo de crenças em saúde de Rosenstock. [dissertação]. Ribeirão Preto (SP): Escola de Enfermagem de Ribeirão Preto/USP; 1997.

8. Ministério da Saúde (BR) Boletim Epidemiológico, Brasília (DF): Ministério da Saúde; 2000.

9. Bardin I. Análise de conteúdo. Lisboa (Portugal): Edições 70; 1977.

10. Rogers CR, Rosemberg RL A pessoa como centro. São Paulo (SP): EPU/EDUSP; 1997. p. 69-90. 